Article

\title{
Gravity Field Model Determination Based on GOCE Satellite Point-Wise Accelerations Estimated from Onboard Carrier Phase Observations
}

\author{
Tangting $\mathrm{Wu}^{1}$, Jiancheng $\mathrm{Li}^{1,2}$, Xinyu Xu ${ }^{1,2, * \mathbb{D}}$, Hui Wei ${ }^{1,2} \mathbb{D}$, Kaifa Kuang ${ }^{1}$ and Yongqi Zhao ${ }^{1}$ \\ 1 School of Geodesy and Geomatics, Wuhan University, 129 Luoyu Road, Wuhan 430079, China; \\ ttwu@whu.edu.cn (T.W.); jcli@sgg.whu.edu.cn (J.L.); hwei@whu.edu.cn (H.W.); kfkuang@whu.edu.cn (K.K.); \\ yqzhao@whu.edu.cn (Y.Z.) \\ 2 Key Laboratory of Geospace Environment and Geodesy of Ministry of Education, Wuhan University, \\ Wuhan 430079, China \\ * Correspondence: xyxu@sgg.whu.edu.cn; Tel.: +86-027-68771783
}

Received: 22 April 2019; Accepted: 13 June 2019; Published: 14 June 2019

\begin{abstract}
GPS-based, satellite-to-satellite tracking observations have been extensively used to elaborate the long-scale features of the Earth's gravity field from dedicated satellite gravity missions. We proposed compiling a satellite gravity field model from Gravity Field and Steady-State Ocean Circulation Explorer (GOCE) satellite accelerations directly estimated from the onboard GPS data using the point-wise acceleration approach, known as the carrier phase differentiation method. First, we composed the phase accelerations from the onboard carrier phase observations based on the sixth-order seven-point differentiator, which can eliminate the carrier phase ambiguity for Low Earth Orbiter (LEO). Next, the three-dimensional (3D) accelerations of the GOCE satellite were estimated from the derived phase accelerations as well as GPS satellite ephemeris and precise clock products. Finally, a global gravity field model up to the degree and order (d/o) 130 was compiled from the 71 days and nearly 2.5 years of 3D satellite accelerations. We also recovered three gravity field models up to d/o 130 from the accelerations derived by differentiating the kinematic orbits of European Space Agency (ESA), Graz, and School of Geodesy and Geomatics (SGG), which was the orbit differentiation method. We analyzed the accuracies of the derived accelerations and the recovered gravity field models based on the carrier phase differentiation method and orbit differentiation method in time, frequency, and spatial domain. The results showed that the carrier phase derived acceleration observations had better accuracy than those derived from kinematic orbits. The accuracy of the recovered gravity field model based on the carrier phase differentiation method using 2.5 years observations was higher than that of the orbit differentiation solutions for degrees greater than 70 , and worse than Graz-orbit solution for degrees less than 70. The cumulative geoid height errors of carrier phase, ESA-orbit, and Graz-orbit solutions up to degree and order 130 were $17.70 \mathrm{~cm}, 21.43 \mathrm{~cm}$, and $22.11 \mathrm{~cm}$, respectively.
\end{abstract}

Keywords: Earth's gravity field; GPS; GOCE; point-wise acceleration approach

\section{Introduction}

The modeling of Earth's gravity field is an essential task in the physical geodesy, and the constructed gravity information can be used for the fields of soild geophysics, oceanography, geodesy, and glaciology [1]. Beginning in the year 2000, several dedicated satellite gravimetry missions, such as the CHAllenging Minisatellite Payload (CHAMP), Gravity Recovery And Climate Experiment (GRACE), and Gravity field and steady-state Ocean Circulation Explorer (GOCE), have significantly improved the accuracy of the static gravity field and its temporal variations by several orders of 
magnitude [2-4]. Although these missions were carried out with different measurement principles, they had a common feature: all were equipped with global positioning system (GPS) receivers to realize the concept known as satellite-to-satellite tracking in high-low mode (SST-hl). SST-hl is a highly sophisticated technique to map the long-wavelength spectrum of the gravity field [5-7].

There are four methods for gravity field recovery that use SST-hl observations: celestial mechanics, energy balance, short-arc, and acceleration methods [8]. According to the types of differentiated acceleration, two acceleration methods exist: the average acceleration method and point-wise acceleration method [9]. Baur et al. [8] and Pail et al. [10] compared the different methods for modeling gravity field models with the GOCE SST-hl data and pointed out that, with the exception of the energy balance method, the other three methods had a comparable performance. The celestial mechanics approach is confronted with a large computational effort due to the integration of the variation equations and a nonlinear system of equations; in the case of the energy balance method, space gravity spectroscopy information is exclusively scalar and not available in all three directions [11-13]. The acceleration method is based on Newton's equation of motion, which balances the gravitational vector with satellite accelerations in the inertial reference frame $[14,15]$. The principle of acceleration approach is simple and has been successfully applied to CHAMP, GRACE, and GOCE SST-hl data analysis [14-19].

The key to recovering the gravity model by the acceleration method is to estimate the satellite accelerations with a high degree of precision. Several approaches have been used to estimate the GPS-based acceleration including orbit differentiation, Doppler differentiation, and carrier phase differentiation approaches [20]. The most commonly used method is performed by double time-differentiating successive trajectories of the moving satellite, also known as the orbit differentiation algorithm. A major drawback to this method is that the accuracy of the differentiated accelerations is strongly dependent on the position precision; an increase or decrease in the number of visible satellites can lead to discontinuities [21]. Another method is the Doppler measurement, which can be used afterward to obtain the satellite's velocity before the satellite accelerations are computed by the first-order derivative of the satellite's velocity. One shortcoming is that the raw Doppler observables may be heavily contaminated by measurement noises [22]. An alternative method is to numerically differentiate the GPS carrier phase observations then obtain both the range rate and range acceleration, which is called the carrier phase differentiation method. This method has been successfully applied in airborne gravimetry $[23,24]$ and satellite gravimetry [25]. The most prominent advantage of this approach is the avoidance of the cycle ambiguity problem and the elimination of systematic errors (e.g., hardware delays from the receiver and GPS satellites) that are common to adjacent epochs [23,25].

Guo et al. [25] adopted the average acceleration approach to recover the gravity field model from satellite accelerations derived from onboard GPS phase measurements. It was shown that the noise of the accelerations derived by the carrier phase differentiation method was lower than that derived by the orbit differentiation method in all three components, especially in the cross-track component, which showed an improvement of about $20 \%$. Thus, the recovered gravity field based on the carrier phase differentiation accelerations had a slightly higher accuracy when compared with the solution based on the orbit differentiation method. It should be noted that Guo et al. [25] estimated the average satellite accelerations in two steps: first, the position differences epoch by epoch were derived directly from the GPS carrier phase measurements; the average satellite accelerations were then obtained with the position differences.

In this study, we proposed to recover the gravity field model based on the point-wise accelerations of the GOCE satellite estimated by the carrier phase differentiation method from the onboard carrier phase observations. This idea has not yet been addressed and differs from the average acceleration approach used for gravity field modeling and the approach of estimating the satellite accelerations in Guo et al. [25]. The paper is organized as follows. Section 2 describes the functional models of satellite acceleration and gravity field determination. Section 3 shows the experimental results. Section 4 discusses the findings of this research, and Section 5 presents our conclusions. 


\section{Methods}

In this paper, the point-wise acceleration approach was applied to recover the gravity field model from the 3D satellite positions, which were computed based on either the carrier phase differentiation method or orbit differentiation algorithm. The functional models for the satellite acceleration determination are given in Section 2.1, and the point-wise acceleration approach for recovering the gravity field model is briefly summarized in Section 2.2.

\subsection{Functional Models for the Determination of the Satellite Acceleration}

\subsubsection{Numerical Differentiation Method}

The numerical differentiation approach is often used to derive the second order derivative from the time series $\{z(t)\}$; a functional model with constant coefficients is fitted to the time series and is subsequently differentiated analytically to obtain its derivatives. There are numerous numerical differentiators that could be used in this approach, including polynomial interpolation, Newton-Gregory differentiation, and Taylor-MacLaurin differentiation [26]. With reference to the analysis of the computational efficiency and performance in Baur et al. [8], we adopted the sixth-order seven-point polynomial fitting in this article. The basic formula for polynomial interpolation depending on the time difference $\tau$ is expressed as [26]:

$$
z\left(t_{0}+\tau_{i}\right)_{N}=\sum_{j=0}^{N} c_{j} \tau_{i}^{j}, \tau_{i}=\left(i-\left[\frac{M}{2}\right]\right) \Delta t
$$

where $z\left(t_{0}+\tau_{i}\right)$ is the arbitrary time series; $i$ is the index of interpolated points; $t_{0}$ is the time at which the polynomial is evaluated; $\tau_{i}$ is the time difference between $t_{0}$ and the actual data point; $M$ is the total number of data points used for the interpolation; $N$ is the degree of the polynomial; $\Delta t$ is the sampling interval; and $c_{j}$ is the polynomial coefficient.

The polynomial was fitted to numbers of neighboring points along the satellite track and then the polynomial coefficients were estimated through a classical least squares [18,26]. Due to polynomial oscillations at the interval boundaries, the polynomial was evaluated at the central point. Finally, we respectively differentiated Equation (1) once and twice, which provided the following formula:

$$
\begin{aligned}
& \dot{z}\left(t_{0}\right)=\mathrm{g}^{T} \cdot z \\
& \ddot{z}\left(t_{0}\right)=h^{T} \cdot z
\end{aligned}
$$

where $\dot{z}\left(t_{0}\right), \ddot{z}\left(t_{0}\right)$ are the first and second derivatives of the time series; $g$ and $h$ are the differentiation operator with the constant coefficients corresponding to the sixth-order seven-point polynomial, which are shown in the following:

$$
\begin{aligned}
& g^{T}=\left[\begin{array}{lllllll}
\frac{-1}{60 \Delta t} & \frac{3}{20 \Delta t} & \frac{-3}{4 \Delta t} & 0 & \frac{3}{4 \Delta t} & \frac{-3}{20 \Delta t} & \frac{1}{60 \Delta t}
\end{array}\right] \\
& h^{T}=\left[\begin{array}{lllllll}
\frac{1}{90 \Delta t^{2}} & \frac{-3}{20 \Delta t^{2}} & \frac{3}{2 \Delta t^{2}} & \frac{-49}{18 \Delta t^{2}} & \frac{3}{2 \Delta t^{2}} & \frac{-3}{20 \Delta t^{2}} & \frac{1}{90 \Delta t^{2}}
\end{array}\right]
\end{aligned}
$$

\subsubsection{Carrier Phase Differentiation Method}

The ionosphere-free carrier phase combination observation between the GPS satellite and LEO satellite receiver is given as follows [21]:

$$
\varphi_{r}^{S}=\rho_{r}^{S}+c\left(d t_{r}-d t^{S}\right)+r e l_{r}^{S}+N_{r}^{S}+\omega_{r}^{S}+\varepsilon_{r}^{S}
$$

where $\varphi_{r}^{S}$ is the ionosphere-free carrier phase combination measurement; $\rho_{r}^{S}$ is the geometric range between the GPS satellite and the LEO satellite receiver antenna; $d t_{r}$ and $d t^{S}$ are the LEO satellite 
and GPS satellite clock offsets, respectively; $r e l_{r}^{S}$ is the relativistic correction; $N_{r}^{S}$ is the carrier phase ambiguity; $\omega_{r}^{S}$ is the wind-up effect; and $\varepsilon_{r}^{S}$ is the remaining unidentifiable noise.

The data pre-processing of raw carrier phase observations focused on the error corrections in Equation (4). The accurate error corrections $\left(\mathrm{rel}_{r}^{S}\right.$ and $\left.\omega_{r}^{S}\right)$ terms were modeled referring to Montenbruck et al. [27] and the satellite receiver clock offsets $d t^{S}$ were interpolated with GPS precise clock products released by International GNSS Service(IGS) [28]. After pre-processing the data, we could construct an item $\hat{\varphi}_{r}^{S}=\varphi_{r}^{S}+c d t^{S}-r e l_{r}^{S}-\omega_{r}^{S}$, and introduce it into Equation (4). We have:

$$
\hat{\varphi}_{r}^{S}=\rho_{r}^{S}+c d t_{r}+N_{r}^{S}+\varepsilon_{r}^{S}
$$

Differentiating Equation (5) yields [24]:

$$
\dot{\hat{\varphi}}_{r}^{S}=\dot{\rho}_{r}^{S}+c d \dot{t}_{r}+\dot{N}_{r}^{S}+\dot{\varepsilon}_{r}^{S}
$$

Given that $\dot{N}_{r}^{S}=0$ when no cycle slip occurs with $\dot{\varepsilon}_{r}^{S}$ omitted, we have:

$$
\dot{\hat{\varphi}}_{r}^{S}=\dot{\rho}_{r}^{S}+c d \dot{t}_{r}
$$

Differentiating Equation (7) then gives:

$$
\ddot{\hat{\varphi}}_{r}^{S}=\ddot{\rho}_{r}^{S}+c d \ddot{t}_{r}
$$

According to the inter-satellite geometric relationship between the GPS satellite and LEO satellite [29], the equations of the LEO's satellite velocity and acceleration are represented as [24]:

$$
\left\{\begin{array}{l}
\dot{\rho}_{r}^{S}-e_{r}^{S} \cdot \dot{x}^{S}=-e_{r}^{S} \cdot \dot{x}_{r} \\
\ddot{\rho}_{r}^{S}-e_{r}^{S} \cdot \ddot{x}^{S}-\frac{1}{\rho_{r}^{S}}\left[\left|\dot{x}_{r}^{S}\right|^{2}-\left(\dot{\rho}_{r}^{S}\right)^{2}\right]=-e_{r}^{S} \cdot \ddot{x}_{r}
\end{array}\right.
$$

where $e_{r}^{S}$ is the unit direction vector between the GPS satellite and LEO satellite receiver; $\dot{x}^{S}$ and $\ddot{x}^{S}$ are the GPS satellite velocity and acceleration; and $\dot{x}_{r}$ and $\ddot{x}_{r}$ are the LEO satellite velocity and acceleration, respectively, which are considered unknown parameters to be determined.

Introducing Equation (7) and Equation (8) into Equation (9), the expression of the carrier phase-based acceleration is derived as follows:

$$
\left\{\begin{array}{l}
-e_{r}^{S} \cdot \dot{x}_{r}+c d \dot{t}_{r}=\dot{\hat{\varphi}}_{r}^{S}-e_{r}^{S} \cdot \dot{x}^{S} \\
-e_{r}^{S} \cdot \ddot{x}_{r}+c d \ddot{t}_{r}=\ddot{\hat{\varphi}}_{r}^{S}-e_{r}^{S} \ddot{x}^{S}-\frac{1}{\rho_{r}^{S}}\left[\left|\dot{x}_{r}^{S}\right|^{2}-\left(\dot{\rho}_{r}^{S}\right)^{2}\right]
\end{array}\right.
$$

where $\dot{x}^{S}$ and $\ddot{x}^{S}$ are provided by IGS precise ephemeris; $\rho_{r}^{S}, \dot{\rho}_{r}^{S}$ and $\boldsymbol{e}_{r}^{S}$ are well known from the study of the line-of-sight accelerations [23]; and $\dot{\hat{\varphi}}_{r}^{S}, \ddot{\hat{\varphi}}_{r}^{S}$ are derived from the GPS carrier phase observations by the sixth-order seven-point differentiation operator, which are separately listed as follows [26]:

$$
\begin{aligned}
& \dot{\hat{\varphi}}_{r}^{S}=\mathrm{g}^{T} \cdot \hat{\varphi}_{r}^{S} \\
& \ddot{\hat{\varphi}}_{r}^{S}=h^{T} \cdot \hat{\varphi}_{r}^{S}
\end{aligned}
$$

where $\dot{\hat{\varphi}}_{r}, \ddot{\hat{\varphi}}_{r}^{S}$ are the first and second derivatives of the ionosphere-free carrier phase combination measurement; $g$ and $h$ are the corresponding impulse response as mentioned above. 


\subsubsection{Orbit Differentiation Method}

For the time series of satellite positions $r(t)$, the polynomial is expressed as:

$$
r\left(t_{0}+\tau_{i}\right)_{N}=\sum_{j=0}^{N} c_{j} \tau_{i}^{j}
$$

where $r\left(t_{0}+\tau_{i}\right)$ is the satellite position; other symbols are mentioned above.

Satellite accelerations can be represented as a linear combination of the satellite positions for the constant sampling interval. The degree of the polynomial should be even and the points for the interpolation should be odd, which guarantees a symmetrical distribution around the central time at which the polynomial is evaluated [26]. In fact, the sampling interval $\Delta t$ of the PKI orbit and the carrier phase observations is not constant. There are two main reasons for choosing the sixth-order seven-point differentiation operator with constant coefficients. First, the differentiation with the constant coefficients is more efficient than the differentiation with non-constant sampling interval, which must estimate the coefficients individually for the seven input points. Second, the percentage of the carrier phase observations with the maximum adjacent epoch difference of continuous seven points greater than $6 \times 10^{-6} \mathrm{~s}$ is less than $1 \%$, which can be ignored. Accordingly, we only used the data with the adjacent epoch difference less than $6 \times 10^{-6} \mathrm{~s}$. Further, we tested the accuracy of the unequally sampled differential accelerations derived with constant differentiation coefficients in inertial reference frame (IRF), as seen in Table 1. The data used for the test is from November 12009 to January 112010 (71 days). According to the Table 1, the accuracy of the differential accelerations is less than $3.039 \times 10^{-7}$, which satisfies the requirement of the gravity field modeling.

Table 1. Accuracy analysis of equally sampled and unequally sampled differential accelerations in IRF (unit: $\mathrm{m} / \mathrm{s}^{2}$ ).

\begin{tabular}{ccccc}
\hline Component & Min & Max & Mean & RMS \\
\hline X & $-3.968 \times 10^{-5}$ & $3.809 \times 10^{-5}$ & $4.522 \times 10^{-10}$ & $3.039 \times 10^{-7}$ \\
Y & $-1.612 \times 10^{-5}$ & $1.563 \times 10^{-5}$ & $-1.649 \times 10^{-10}$ & $1.105 \times 10^{-7}$ \\
Z & $-1.457 \times 10^{-5}$ & $1.313 \times 10^{-5}$ & $1.978 \times 10^{-10}$ & $1.204 \times 10^{-7}$ \\
\hline
\end{tabular}

\subsection{Point-Wise Acceleration Approach for Recovering Gravity Field Model}

The point-wise acceleration approach for recovering the gravity field model is based on Newton's equation of motion in the inertial reference frame [18]:

$$
\ddot{\boldsymbol{r}}-\boldsymbol{a}_{c f}-\boldsymbol{a}_{n c f}=R_{E}^{I} \nabla V(r, \theta, \lambda)
$$

where $\ddot{\boldsymbol{r}}$ is the satellite acceleration; $\boldsymbol{a}_{c f}$ denotes the time-variable gravity field signals; $\boldsymbol{a}_{n c f}$ is the non-gravitational acceleration; $R_{E}^{I}$ denotes the rotation matrix from the Earth-fixed reference frame to the inertial reference frame; $\nabla$ is regarded as the gradient symbol; and $V$ is the static gravitational potential.

Although the GOCE satellite makes use of a drag-free control system in the flight direction that has largely compensated for the non-gravitational perturbation (mainly air-drag), it is indispensable to accommodate for the systematic errors caused by satellite attitude control, the resulting movement of center-of-mass, and the inconsistent derivation scale factors of each accelerometers. 1-cpr empirical acceleration parameters were often used to absorb the remaining non-gravitational accelerations [30]. We also estimated SH coefficients by estimating the 1 cpr empirical parameters. There was not a significant difference in the solution without estimating the empirical parameters. Accordingly, we preferred to determine SH coefficients without estimating the empirical parameters. All time-variable gravity field signals that include third-body accelerations, tidal accelerations, and relativistic effects were computed according to background models [31-34]. 
As described in Heiskanen and Moritz [35], the gravitational potential $V$ is usually represented in spherical harmonic series expansion:

$$
V(r, \theta, \lambda)=\frac{G M}{R} \sum_{n=0}^{N}\left(\frac{R}{r}\right)^{n+1} \sum_{m=0}^{n}\left(\bar{C}_{n m} \cos m \lambda+\bar{S}_{n m} \sin m \lambda\right) \bar{P}_{n m}(\cos \theta)
$$

where $(r, \theta, \lambda)$ denotes the spherical polar coordinates with radius, co-latitude, and longitude; GM is the geocentric gravitational constant; $R$ is the Earth's mean radius; $\bar{P}_{n m}$ denotes the fully normalized associated Legendre functions of degree $n$ and order $m ; N$ is the maximum spherical harmonic degree; and $\bar{C}_{n m}$ and $\bar{S}_{n m}$ are the geopotential coefficients. Combining Equations (13) and (14), a regression model can be formed:

$$
\mathbf{y}=B x+\Delta
$$

Therein, $\mathbf{y}$ denotes the observation vectors; $\Delta$ denotes the error vectors; $B$ is the design matrix; and $x$ is the unknown geopotential coefficient.

Using Equation (15), the geopotential coefficients can be estimated based on the least-squares method from the satellite accelerations. To guarantee an unbiased estimate, we did not use a regularization technique in the least squares.

\section{Results}

This section presents the experimental results including the GOCE real data description and preprocessing in Section 3.1, the noise analysis of satellite accelerations obtained from both the orbit differentiation method and carrier phase differentiation method in Section 3.2, and the accuracy assessment of the derived gravity field models in Section 3.3.

\subsection{Experimental Data and its Preprocessing}

To verify the feasibility of the proposed carrier phase differentiation method, the officially released GOCE Level $1 \mathrm{~b}$ and SST_PSO_2 products [36,37] for 71 days (from November 12009 to January 112010 ) with a $1 \mathrm{~s}$ sampling interval were used first for testing. The data period was in accordance with the period used for the computation of the first-generation gravity field model released by the GOCE High-Level Processing Facility [38]. The SST_PSO_2 product contains the kinematic orbits (SST_PKI_2), reduced-dynamic orbits (SST_PRD_2), and the Earth's orientation quaternions (SST_PRM_2). The SST_PRM_2 data are used to transform accelerations from an Earth-fixed reference frame to an inertial reference frame. The accuracy of the GOCE satellite official scientific orbit data over the entire mission was up to $2 \mathrm{~cm}$ in each direction, i.e., nearly $3.5 \mathrm{~cm}$ in three dimensions [39]. For the carrier phase differentiation method, the time of all of the used data was synchronized by interpolation to coincide with the time of the original carrier phase observations. For the orbit differentiation method, the time of all data used for gravity field modeling was synchronized by interpolation to coincide with the time of raw kinematic orbits.

For the orbit differentiation method, three kinematic orbits were used for gravity field modeling. One was the released SST-PKI-2 product by ESA, hereafter denoted as the ESA-orbit. The other was provided by the Institute of Theoretical Geodesy and Satellite Geodesy, Graz University of Technology [40], hereafter denoted as the Graz-orbit. The third was the kinematic orbit estimated by our own product, hereafter denoted as the SGG-orbit. In addition, the background force models used for computing the time-variable accelerations (e.g., third-body accelerations, tidal accelerations, and relativistic effects) are listed in Table 2. 
Table 2. Background force models.

\begin{tabular}{cc}
\hline Category & Description \\
\hline Third-body perturbations & DE405 [31] \\
Solid Earth tides & IERS Conventions 2010 [32] \\
Ocean tides & EOT11a [33] \\
Solid Earth pole tides & IERS Conventions 2010 \\
Ocean pole tides & Desai [34] \\
General relativistic effects & IERS Conventions 2010
\end{tabular}

PKI orbits are normally used to recover the Earth's gravity field because they are independent of a priori gravity field models [39]. However, due to the geometric conditions of GPS satellites, some data gaps or lower quality data always exists in the PKI orbits. The number of the data gaps for the three PKI orbits and carrier phase derived accelerations for 71 days is shown in Table 3 . The data derived by the carrier phase differentiation method included more data gaps than other methods. In addition, we subtracted reference accelerations computed with the model DGM-1S [41] from the differential accelerations to obtain residual accelerations. Then, the residual accelerations exceeding three times the corresponding standard deviations were identified as outliers and discarded according to the method used in Guo et al. [25]. The corresponding standard deviations were estimated based on the method with five iterations, and they were 1.12, 0.81 and $1.90 \mathrm{mGal}$, respectively, for the three components of the carrier phase-derived accelerations. These values were also used for the gross error detection for the other three methods. The gross error ratios of the accelerations derived from four different methods are shown in Table 3. According to Table 3, the least number of gross errors in accelerations was obtained from the carrier phase method.

Table 3. Orbit data gap ratio and gross error elimination ratio of the residual accelerations of 71 days.

\begin{tabular}{ccccc}
\hline & \multicolumn{4}{c}{ Method } \\
\cline { 2 - 5 } & Carrier Phase & ESA-Orbit & Graz-Orbit & SGG-Orbit \\
\hline Data gap & $9.712 \%$ & $5.702 \%$ & $3.533 \%$ & $5.667 \%$ oo \\
\hline $\begin{array}{c}\text { Gross error } \\
\text { elimination }\end{array}$ & $9.529 \%$ & $12.257 \%$ & $11.963 \%$ & $10.679 \%$ \\
\hline
\end{tabular}

Figure 1 shows the spatial distribution of gross errors in the residual accelerations in three directions (radial, along-track, and cross-track) derived by the carrier phase differentiation method and the orbit differentiation method. More gross errors and large errors were located close to the geomagnetic poles in the case of both the carrier phase differentiation method and the orbit differentiation method. Furthermore, the radial residual accelerations were noisier than the other two components, which is consistent with the results presented in Table 4. 

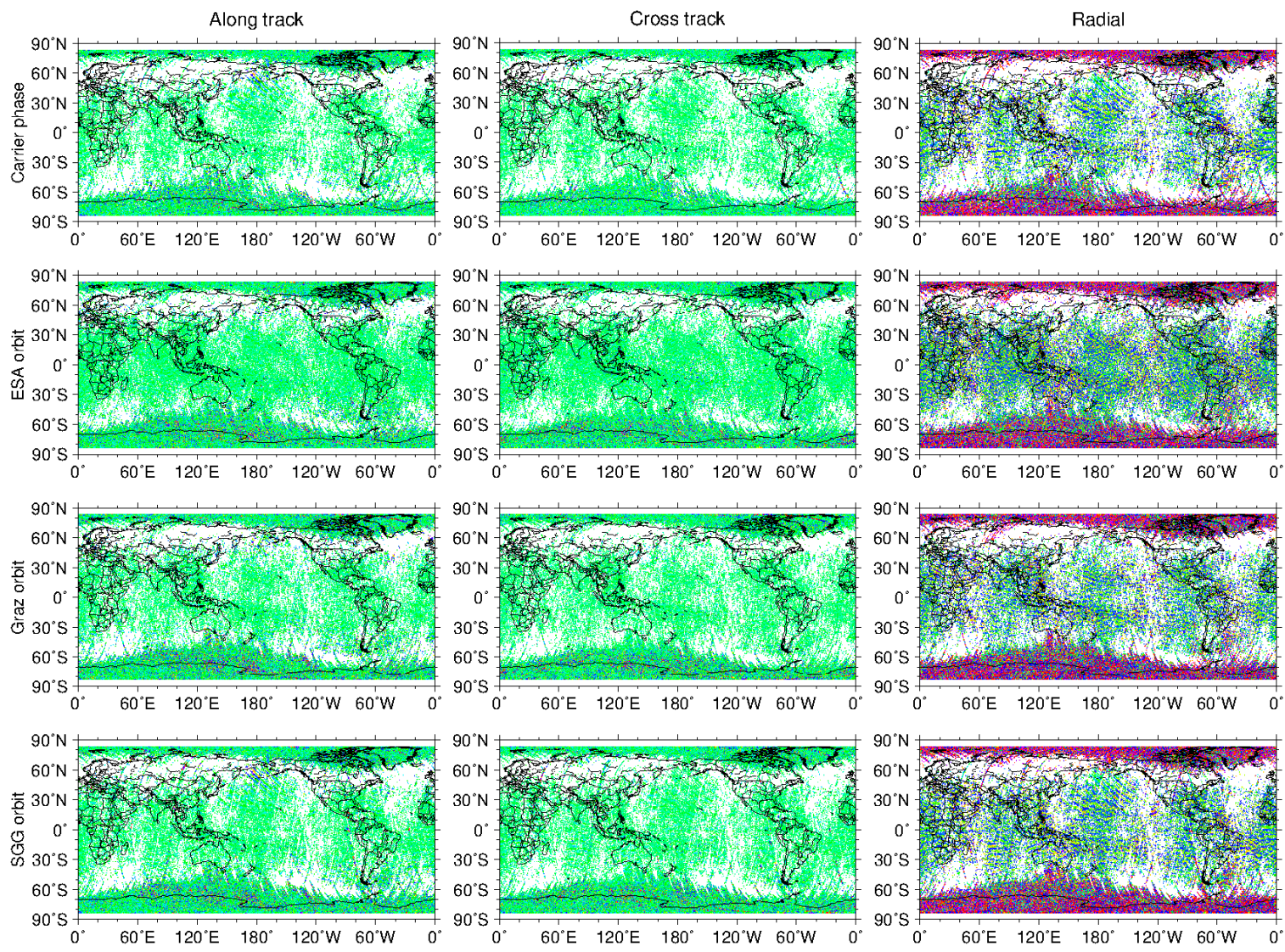

$-10$

$-5$

0

5

10

Figure 1. Spatial distribution of the gross errors with regard to the residual accelerations (unit: $\mathrm{m} / \mathrm{s}^{2}$ ).

\subsection{Accuracy Analysis of Residual Accelerations}

Using the carrier phase/orbit differentiation method, we derived four acceleration sets with gross error elimination applied from the datasets described in the previous section. To analyze the accuracy of the derived accelerations, residual accelerations were obtained by subtracting the prior accelerations derived from the DGM-1S model from the differentiated accelerations. Statistics of the residual accelerations derived by the four different methods are listed in Table 4. According to the root mean square (RMS) in Table 4, the accelerations obtained by the carrier phase differentiation method had a slightly higher precision than the others in the three directions. In consideration of the 3D-RMS in the Table 4, the accuracy of the results obtained by the carrier phase differentiation method were $20 \%, 6 \%$, and $12 \%$ higher than those obtained by the ESA-orbit differentiation, the Graz-orbit differentiation, and the SGG-orbit differentiation, respectively. Our results derived by the two different methods were close to each other. The main reason for this is that the same carrier phase data and similar processing strategies were adopted for the carrier phase differentiation method and the orbit differentiation method. Furthermore, the RMS of the residuals revealed that the precision of the radial was worse than those of the other two components, which is similar to the case of gross error detection in the derived accelerations.

Table 4. Error statistics of the residual accelerations of 71 days (unit: $\mathrm{m} / \mathrm{s}^{2}$ ).

\begin{tabular}{ccccccc}
\hline Method & Component & Min & Max & Mean & RMS & 3D-RMS \\
\hline \multirow{2}{*}{ Carrier } & Along-track & $-2.962 \times 10^{-5}$ & $2.962 \times 10^{-5}$ & $1.656 \times 10^{-9}$ & $1.115 \times 10^{-5}$ & \\
phase & Cross-track & $-2.508 \times 10^{-5}$ & $2.508 \times 10^{-5}$ & $3.775 \times 10^{-10}$ & $8.104 \times 10^{-6}$ & $1.241 \times 10^{-5}$ \\
& Radial & $-6.405 \times 10^{-5}$ & $6.405 \times 10^{-5}$ & $2.842 \times 10^{-9}$ & $1.909 \times 10^{-5}$ & \\
\hline
\end{tabular}


Table 4. Cont.

\begin{tabular}{ccccccc}
\hline Method & Component & Min & Max & Mean & RMS & 3D-RMS \\
\hline \multirow{3}{*}{ ESA-orbit } & Along-track & $-3.921 \times 10^{-5}$ & $3.921 \times 10^{-5}$ & $-2.706 \times 10^{-9}$ & $1.231 \times 10^{-5}$ & \\
& Cross-track & $-3.699 \times 10^{-5}$ & $3.699 \times 10^{-5}$ & $7.520 \times 10^{-10}$ & $9.675 \times 10^{-6}$ & $1.557 \times 10^{-5}$ \\
& Radial & $-8.975 \times 10^{-5}$ & $8.975 \times 10^{-5}$ & $2.410 \times 10^{-9}$ & $2.408 \times 10^{-5}$ & \\
\hline \multirow{3}{*}{ Graz-orbit } & Along-track & $-3.664 \times 10^{-5}$ & $3.664 \times 10^{-5}$ & $2.471 \times 10^{-9}$ & $1.221 \times 10^{-5}$ & \\
& Cross-track & $-3.634 \times 10^{-5}$ & $3.634 \times 10^{-5}$ & $-3.226 \times 10^{-9}$ & $1.211 \times 10^{-6}$ & $1.319 \times 10^{-5}$ \\
& Radial & $-7.023 \times 10^{-5}$ & $7.023 \times 10^{-5}$ & $8.513 \times 10^{-9}$ & $2.341 \times 10^{-5}$ & \\
\hline \multirow{3}{*}{ SGG-orbit } & Along-track & $-3.692 \times 10^{-5}$ & $3.692 \times 10^{-5}$ & $4.038 \times 10^{-9}$ & $1.123 \times 10^{-5}$ & \\
& Cross-track & $-3.669 \times 10^{-5}$ & $3.669 \times 10^{-5}$ & $4.498 \times 10^{-9}$ & $1.223 \times 10^{-5}$ & $1.422 \times 10^{-5}$ \\
& Radial & $-6.664 \times 10^{-5}$ & $6.664 \times 10^{-5}$ & $6.468 \times 10^{-9}$ & $2.221 \times 10^{-5}$ & \\
\hline
\end{tabular}

We also plotted the square root of the power spectral density (PSD) of 1 day residual accelerations derived by four different methods, which are shown in Figure 2. As seen in the Figure 2, the PSD curves of the residual accelerations of the four cases were similar, especially for the carrier phase and SGG-orbit differentiated accelerations, which showed that the errors increased with an increase in the frequency when $f<0.015 \mathrm{~Hz}$. This character is consistent with the inherent property of the numerical differentiation, i.e., the time series signal will be multiplied by $\omega^{2}$ in the frequency domain after applying numerical differentiation, where $\omega$ is the frequency. In addition, the errors of the radial component were about twice that of the other two components. Simultaneously, the magnitudes of the square-root PSDs derived from the different methods were slightly different. For all three components, the magnitude in the case of the carrier phase method was slightly lower than those in the case of the SGG-orbit method in the high frequency part $(\sim f>0.003 \mathrm{~Hz})$.
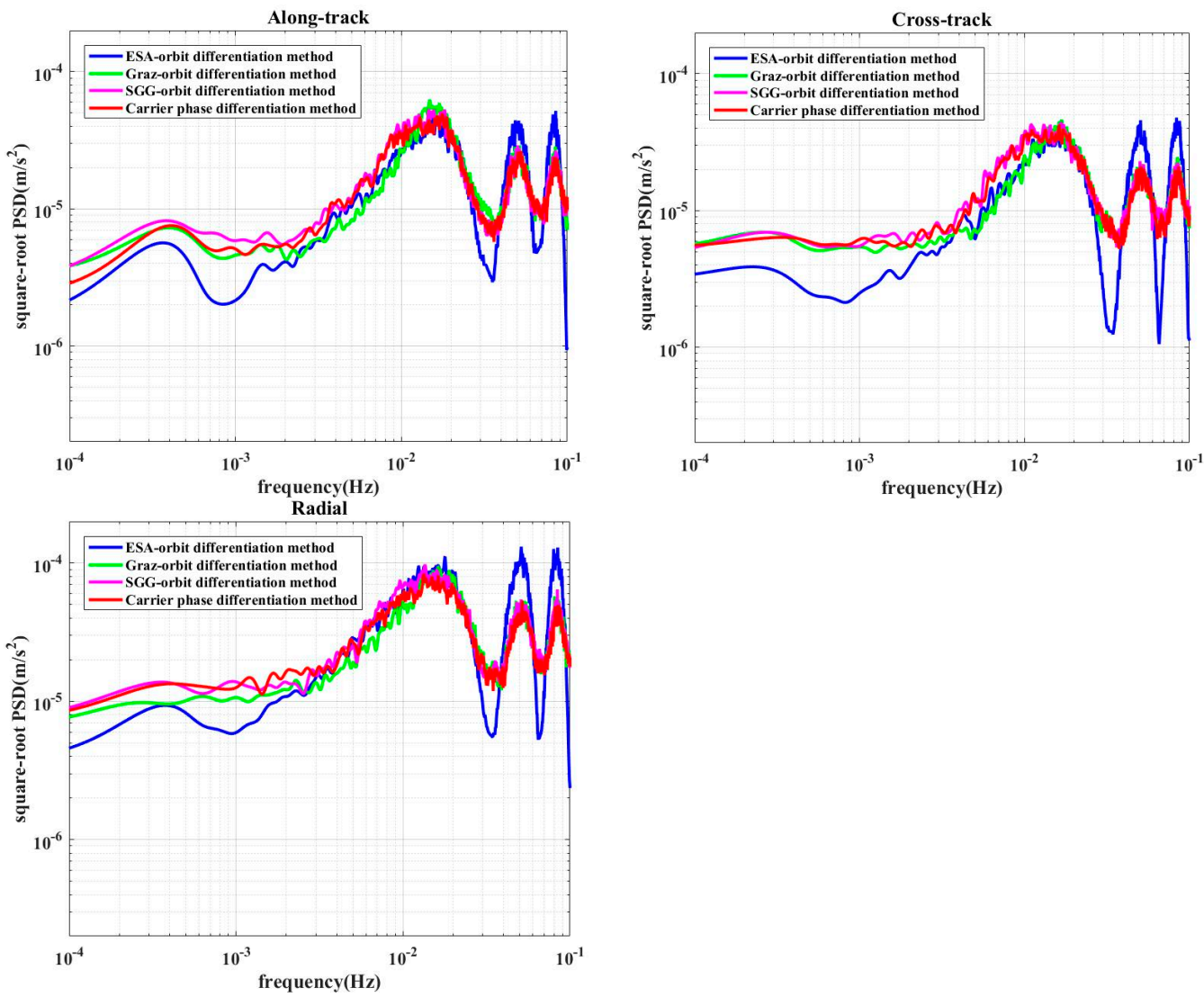

Figure 2. PSDs of the residual accelerations derived by the four different methods. (Top-left) Along-track; (Top-right) Cross-track; (Bottom) Radial (unit: $\mathrm{m} / \mathrm{s}^{2} / \mathrm{Hz}^{1 / 2}$ ). 


\subsection{Gravity Field Solutions}

\subsubsection{Solutions estimated from 71 days of observations}

We estimated four satellite gravity field models up to $\mathrm{d} / \mathrm{o} 130 \mathrm{using}$ the point-wise acceleration method from the accelerations derived in the previous section. The EIGEN-6C4 model up to d/o 130 was used as the reference model to validate the estimated gravity field models. This model was characterized by a higher accuracy because it was constructed by a combination of multi-source gravity data such as GOCE, GRACE, and LAGEOS satellite observations, satellite altimetry, and ground gravity data [42]. Note that the empirical variance-covariance matrices used here were constructed directly by using residual accelerations.

From the perspective of gravity spectroscopy, Figure 3 depicts the residual spherical harmonic spectra with a $\log 10$ scale of the estimated solutions when compared with the EIGEN-6C4 model. According to Figure 3, the distribution of all of the residual harmonic coefficient spectra were similar. The noise in the spherical harmonic coefficients increased with the spherical harmonic degree and the sectorial and near sectorial harmonic coefficients had better accuracy, which is an inherent feature of the SST-hl observations used for gravity field modeling [29]. The near sectorial harmonic coefficients based on the Graz-orbit differentiated accelerations performed best, and the accuracy of the zonal and near zonal coefficients was worse. Furthermore, the high degree harmonic coefficients estimated by the carrier phase method performed the best.
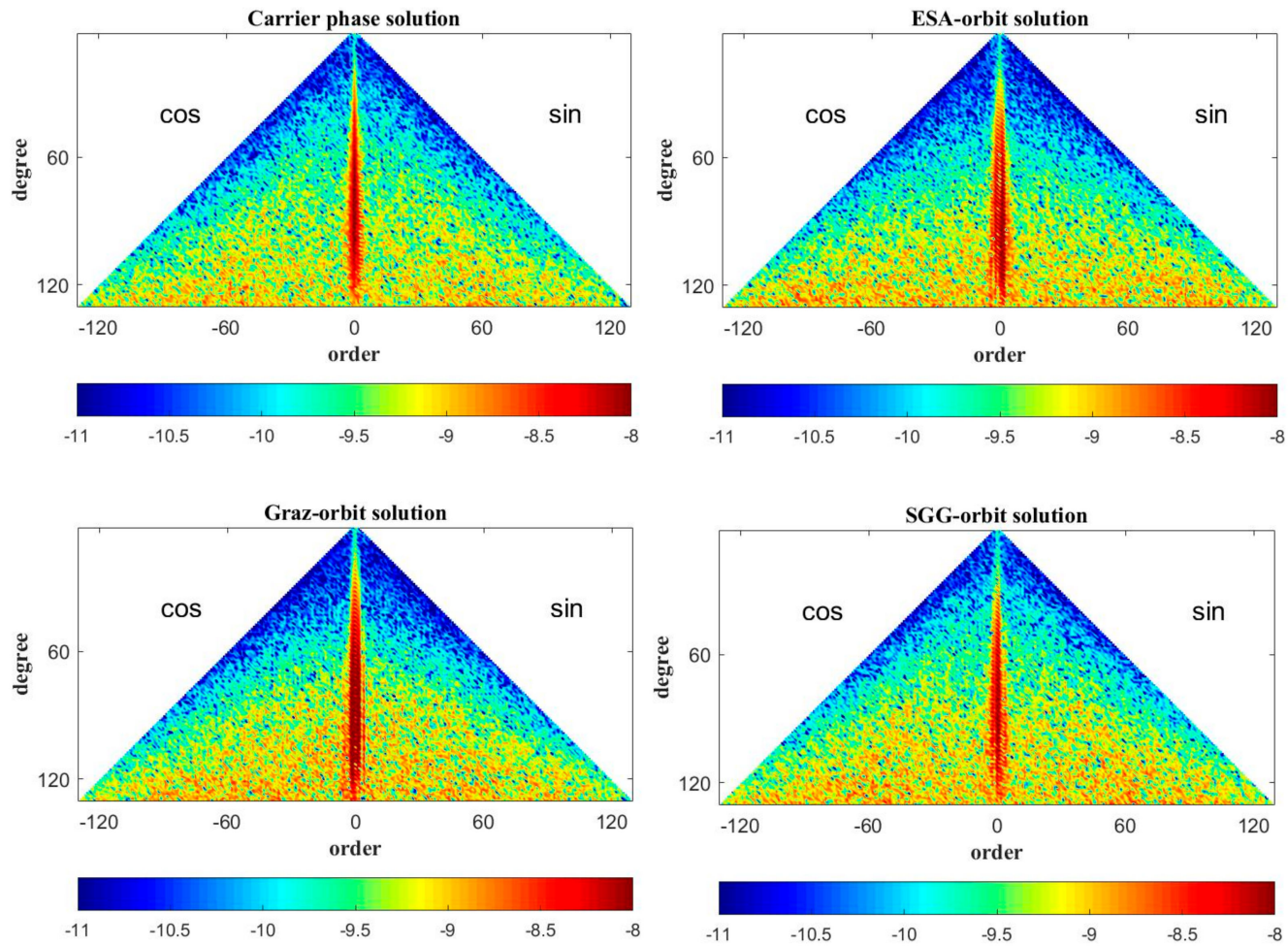

Figure 3. Spherical harmonics triangle of the estimated geopotential coefficients when compared with EIGEN-6C4.

To assess the performance of the recovered gravity field models in the spectral domain, the Degree-Error Root Mean Square (DE-RMS) values and cumulative geoid height differences $\left(\sigma_{N_{n}}^{(C)}\right)$ were computed according to the following formula [18]:

$$
D E-R M S_{n}=\sqrt{\frac{1}{2 n-8} \sum_{m=5}^{n}\left[\left(\bar{C}_{n m}^{e s t}-\bar{C}_{n m}^{r e f}\right)^{2}+\left(\bar{S}_{n m}^{e s t}-\bar{S}_{n m}^{r e f}\right)^{2}\right]}
$$




$$
\sigma_{N_{n}}^{(C)}=R \sqrt{\sum_{n} \frac{1}{2 n-8} \sum_{m=5}^{n}\left[\left(\bar{C}_{n m}^{e s t}-\bar{C}_{n m}^{r e f}\right)^{2}+\left(\bar{S}_{n m}^{e s t}-\bar{S}_{n m}^{r e f}\right)^{2}\right]}
$$

where $\left(\bar{C}_{n m}^{e s t}, \bar{S}_{n m}^{e s t}\right)$ are the estimated spherical harmonic coefficients, and $\left(\bar{C}_{n m}^{r e f}, \bar{S}_{n m}^{r e f}\right)$ denote the coefficients of the reference gravity field model; $R$ denotes the Earth's mean radius. Additionally, to account for the polar gap problem, neglecting $\mathrm{m}<5$ is applicable for the computation of the DE-RMS and cumulative geoid height differences.

Figure 4 shows the DE-RMS of the four recovered models. Table 5 presents the cumulative geoid height differences for the degrees from 10 to 130. From Figure 4 and Table 5, for the whole frequency band of the recovered model, the carrier phase differentiation method had a comparable performance with the orbit differentiation method. The cumulative geoid height difference of the carrier phase solution up to 130 was the smallest, which was $37.02 \mathrm{~cm}$. The geoid height differences of the recovered gravity field solutions are shown in Table 6, and their spatial distributions are shown in Figure 5. We applied a 500-km Gaussian filter to suppress the high-frequency noise of the gravity field [43]. Table 6 demonstrates the errors of the geoid heights derived by the carrier phase differentiation method, which were close to those obtained by the ESA-orbit differentiation method and is consistent with the results seen in Table 5. According to Figure 5, the large errors were located near the geomagnetic equator and polar region in the solutions, which is consistent with the situation of the residual accelerations shown in Section 3.2.

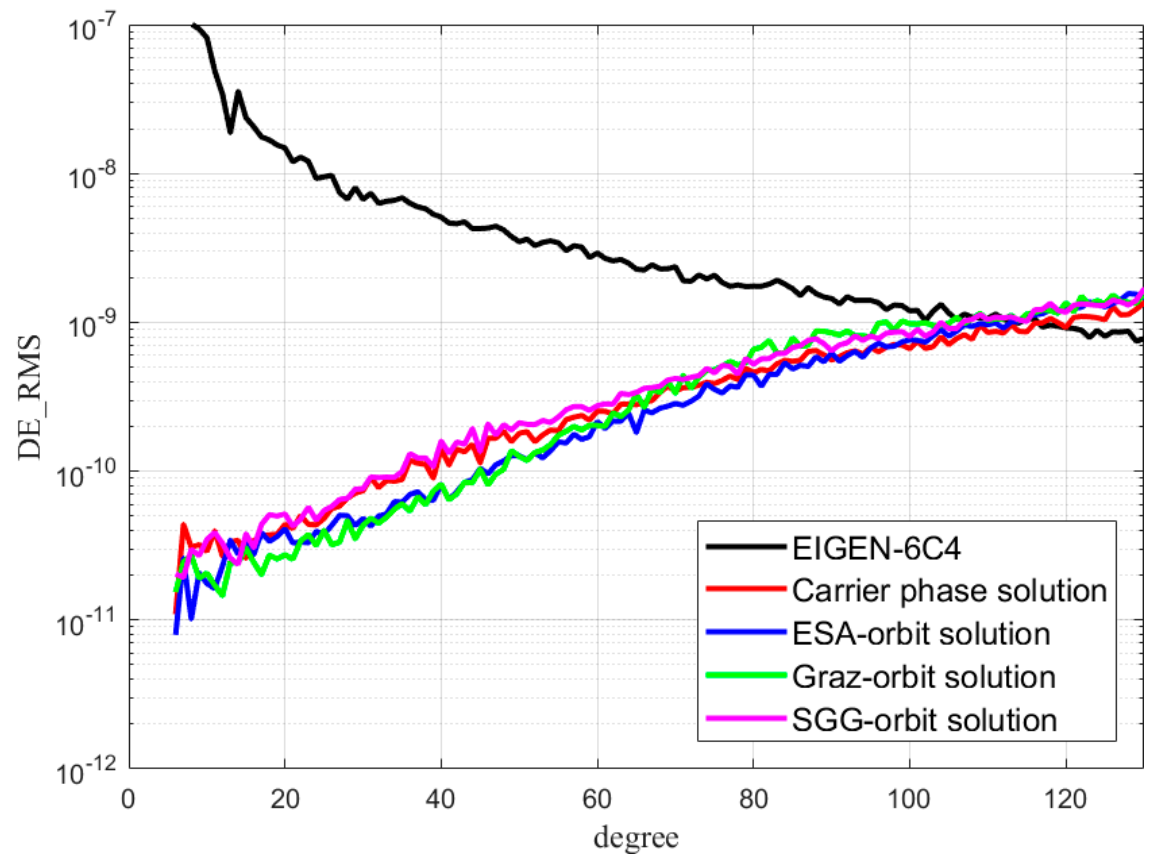

Figure 4. Degree-Error Root Mean Square(DE-RMS) of the recovered spherical harmonic coefficients w.r.t. EIGEN-6C4. 
Table 5. Cumulative geoid height differences (unit: $\mathrm{cm}$ ) w.r.t. EIGEN-6C4 up to different degrees.

\begin{tabular}{ccccc}
\hline Degree & $\begin{array}{c}\text { Carrier Phase } \\
\text { Solution }\end{array}$ & $\begin{array}{c}\text { ESA-Orbit } \\
\text { Solution }\end{array}$ & $\begin{array}{c}\text { Graz-Orbit } \\
\text { Solution }\end{array}$ & $\begin{array}{c}\text { SGG-Orbit } \\
\text { Solution }\end{array}$ \\
\hline 10 & 0.09 & 0.08 & 0.07 & 0.08 \\
30 & 0.67 & 0.65 & 0.48 & 0.71 \\
50 & 2.28 & 1.88 & 1.51 & 2.54 \\
70 & 5.50 & 4.43 & 4.70 & 6.32 \\
90 & 11.71 & 10.34 & 13.97 & 14.09 \\
110 & 21.98 & 21.30 & 26.68 & 26.28 \\
130 & 37.02 & 39.19 & 46.72 & 46.96 \\
\hline
\end{tabular}

Table 6. Statistics of the geoid height differences (unit: m) w.r.t. EIGEN-6C4 with the $500 \mathrm{~km}$ Gaussian smoothing applied.

\begin{tabular}{ccccc}
\hline Method & Min & Max & Mean & RMS \\
\hline Carrier phase solution & -0.469 & 0.201 & $3.531 \times 10^{-3}$ & 0.068 \\
ESA-orbit solution & -0.360 & 0.331 & $1.001 \times 10^{-2}$ & 0.060 \\
Graz-orbit solution & -0.728 & 0.261 & $5.091 \times 10^{-3}$ & 0.096 \\
SGG-orbit solution & -0.365 & 0.187 & $1.251 \times 10^{-3}$ & 0.063 \\
\hline
\end{tabular}

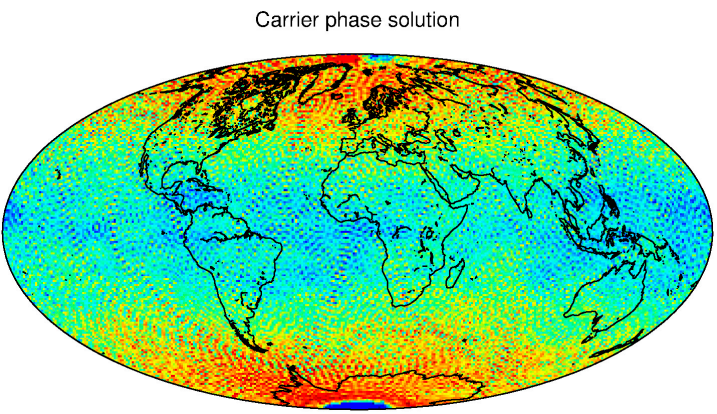

Graz-orbit solution
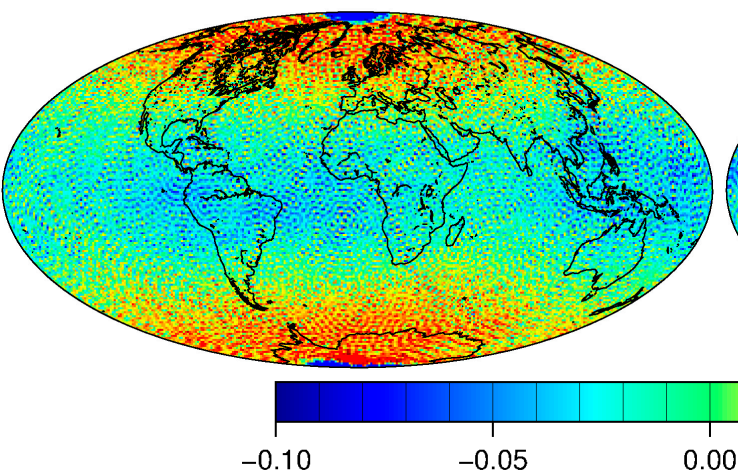

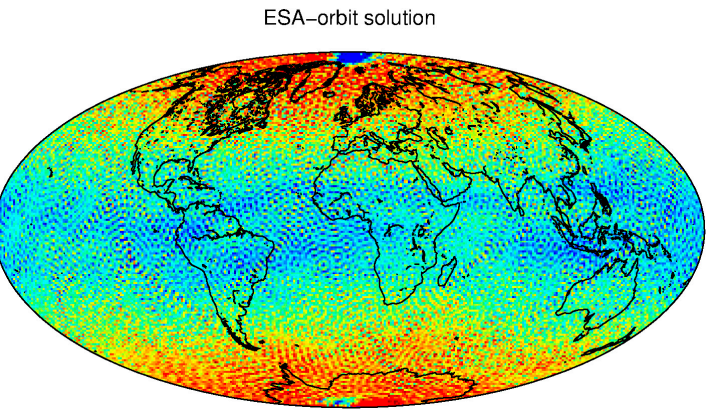

SGG-orbit solution

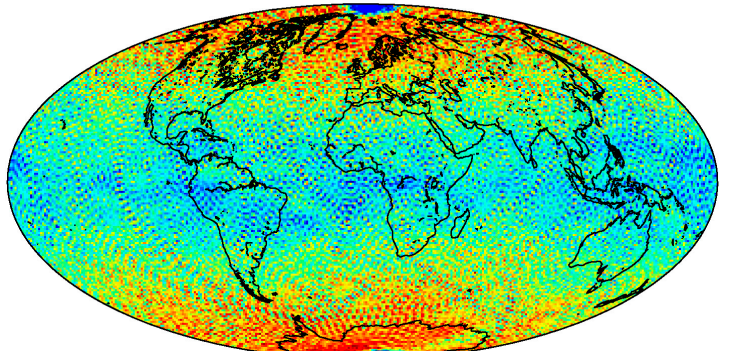

$(\mathrm{m})$

Figure 5. Geoid height errors of the recovered spherical harmonic coefficients w.r.t. EIGEN-6C4 with the $500 \mathrm{~km}$ Gaussian smoothing applied.

\subsubsection{Solutions estimated from 2.5 years of observations}

Finally, we extend GOCE data span to the period from November 2009 to July 2012 to compile the carrier phase, ESA-orbit, and Graz-orbit solutions up to degree and order 130. This data period is comparable with the one used in Guo et al. [25], and the gravity field model DGM-1S was also used as a reference model to access the quality of the obtained three gravity field solutions similar to Guo et al. [25]. The model DGM-1S is based on data from the GRACE and GOCE satellite gravity missions [41]. Figure 6 depicts the DE-RMS of three solutions. Table 7 shows the cumulative geoid height differences w.r.t. DGM-1S for the degrees up to d/o 130. Figure 7 presents the spatial distribution 
of the recovered gravity field solutions with the 500-km Gaussian smoothing filter applied. There are obvious systematic errors along the geomagnetic equator, especially for the solutions obtained from the orbit differentiation method, which is the same situation in Guo et al. [25].

Table 7. Cumulative geoid height differences (unit: $\mathrm{cm}$ ) w.r.t. DGM-1S up to different degrees.

\begin{tabular}{cccc}
\hline Degree & Carrier Phase Solution & ESA-Orbit Solution & Graz-Orbit Solution \\
\hline 10 & 0.07 & 0.05 & 0.03 \\
30 & 0.38 & 0.36 & 0.28 \\
50 & 1.08 & 1.01 & 0.97 \\
70 & 2.60 & 2.64 & 2.76 \\
90 & 5.58 & 6.02 & 6.57 \\
110 & 10.36 & 11.76 & 12.71 \\
130 & 17.70 & 21.43 & 22.11 \\
\hline
\end{tabular}

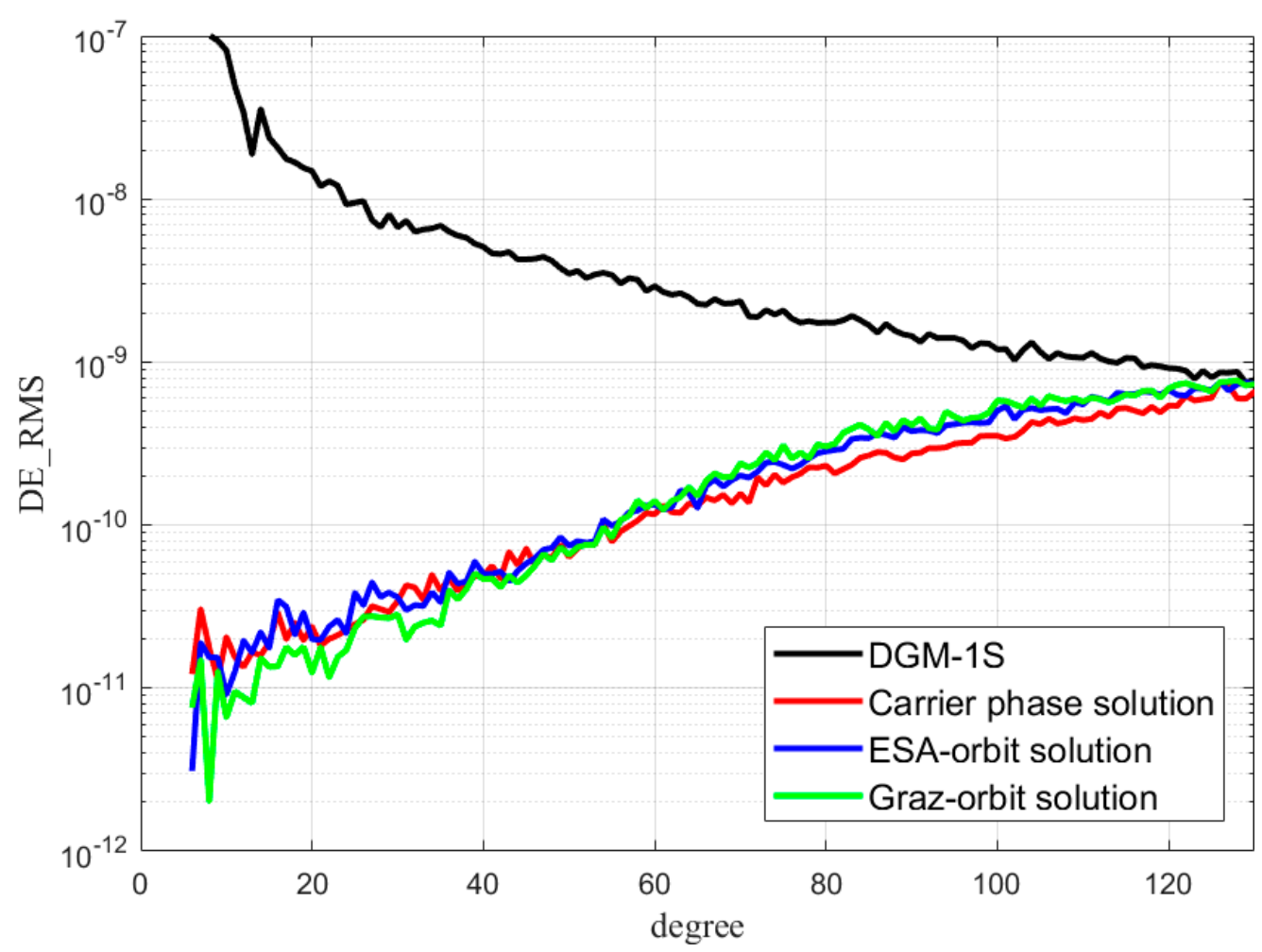

Figure 6. DE-RMS of the recovered spherical harmonic coefficients w.r.t. DGM-1S. 


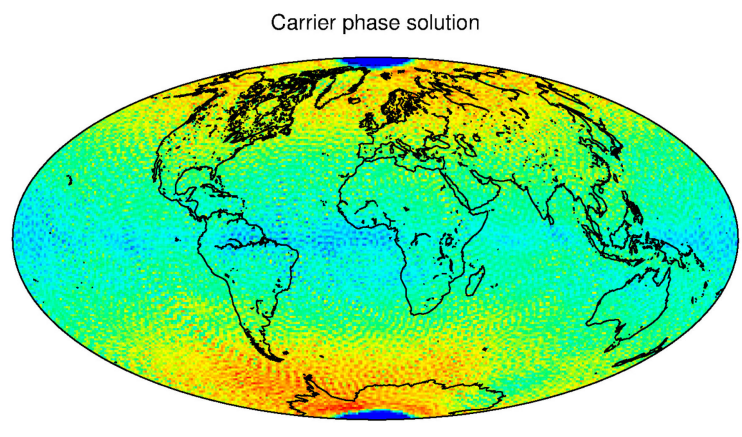

ESA-orbit solution

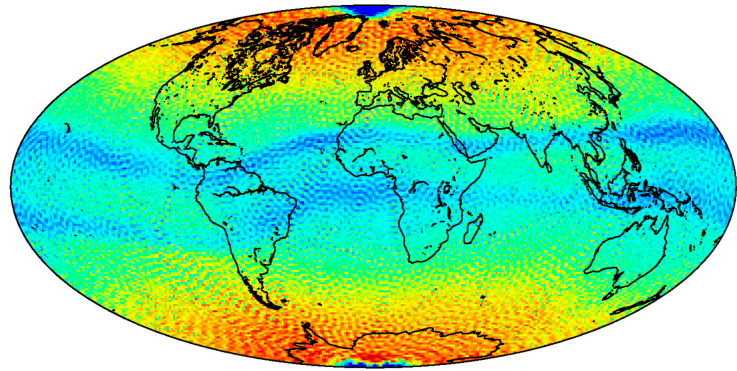

Graz-orbit solution

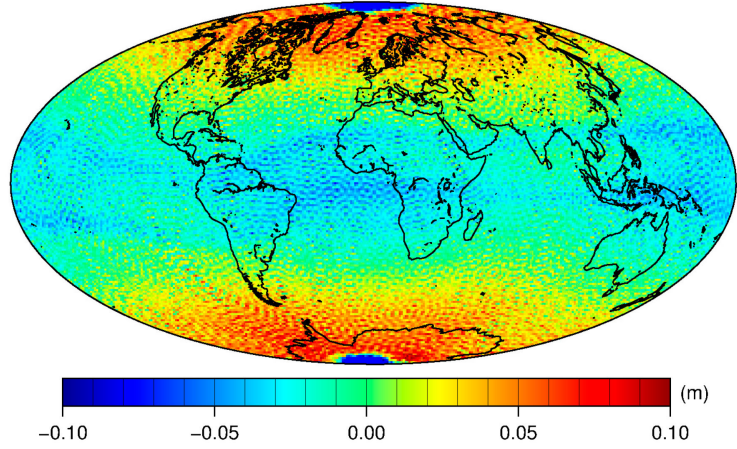

Figure 7. Geoid height errors of the recovered spherical harmonic coefficients w.r.t. DGM-1S with the $500 \mathrm{~km}$ Gaussian smoothing applied.

\section{Discussion}

According to Figures 1 and 2 as well as Table 4, the derived radial accelerations were noisier than the other two components. This can be explained by a relatively low accuracy of the GPS positioning in the radial direction, which is caused by the geometric configuration of the satellite constellation [44-46]. Additionally, the along-track accelerations performed weaker than the cross-track component, which was caused by an increase or decrease in the number of visible satellites because geometry changes can inevitably degrade the position solution and create large acceleration errors [46]. Therefore, stringent position accuracies and poor tolerance of geometry changes are the main drawbacks of the orbit differentiation method. However, the carrier phase differentiation method is more robust because no ambiguity resolution is required. In addition, the distribution of gross errors in Figure 1 and geoidal errors in Figures 5 and 7 were geographically correlated and highly inhomogeneous; large errors were mainly located close to the geomagnetic poles. There are two reasons for this situation: the poor observation geometry in geographical polar region, which is very close to the geomagnetic polar region; and the ionospheric scintillation effects, which cause short-period irregular changes in the phase and amplitude of signal [44].

According to Figures 4 and 6 as well as Tables 5 and 7, the carrier phase solution showed a slightly better performance than the other solutions derived from the orbits only in the high-frequency portion; the 71-day solution corresponds to degree $n>100$ and 2.5-year solution corresponds to degree $n>70$. 
In this frequency band, the acceleration noise of the carrier phase solution was lower than the others, as shown in Figure 2. The degrees 100 and 70 approximately correspond to the frequency 0.019 and $0.013 \mathrm{~Hz}$. In comparison with the Graz-orbit solution, the carrier phase solution had a lower accuracy for the degree $n<70$ and a higher accuracy for $n>70$, which is consistent with frequencies less than $0.013 \mathrm{~Hz}$ (approximately corresponding to the degree 70). Moreover, the cumulative geoid height differences of the Graz-orbit, ESA-orbit, and carrier phase solutions up to degree 50 were 0.97, 1.01, and $1.08 \mathrm{~cm}$, respectively, as seen in in Table 7, which shows that the Graz-orbit solution had the highest precision for the degrees lower than 50. In Table 5, the carrier phase solution was better than the SGG-orbit solution for almost all degrees ( $n>30)$, and the accuracy improvement of geoid height up to $\mathrm{d} / \mathrm{o} 130$ was 21\%, which is similar to that in Guo et al. [25]. A comparison of Figures 4 and 6 as well as Tables 5 and 7 indicates that the longer data period has improved the solutions significantly along the entire frequency band. In addition, as depicted in Figures 5 and 7, the pronounced errors along the geomagnetic equator were observed in all solutions. This is a result of the high electron density in addition to large short-term variations in the ionosphere near the geomagnetic equator $[47,48]$.

As shown in Figure 3, the zonal and near-zonal spherical harmonics coefficients of the recovered models were worse than the other coefficients due to the fact that the GOCE satellite flies in a sun synchronous orbit with an inclination of $96.7^{\circ}$, which causes the ill-posed problem of the least squares used for recovering the gravity field model $[49,50]$. However, zonal harmonic coefficients estimated by the carrier phase differentiation method were slightly better than those from the orbit differentiation method.

\section{Conclusions}

The point-wise acceleration approach was proposed to recover the gravity field model based on satellite accelerations directly estimated from the GOCE's onboard carrier phase observations. The satellite accelerations derived by the carrier phase differentiation method had a slightly better quality in terms of time-domain than those derived by the kinematic orbit differentiation method, respectively. A static gravity field model up to degree and order 130 was compiled from 71 days and 2.5 years of GOCE SST-hl data by the carrier phase differentiation method. Additionally, the gravity models were estimated based on the conventional orbit differentiation method from the ESA's, Graz's, and SGG's PKI orbits. In comparison with the reference models (EIGEN-6C4 and DGM-1S) in accordance with DE-RMS, the 71-day carrier phase solution was slightly better than the SGG-orbit solution in the entire frequency band; however, it showed a worse performance in the low frequency part than the ESA-orbit solution and Graz-orbit solution. Furthermore, the 2.5-year carrier phase solution had the best accuracy for the degrees greater than 70, and its cumulative geoid height error up to $\mathrm{d} / \mathrm{o} 130$ was the lowest, which indicates that the proposed approach in this paper shows very good performance for gravity field modeling from the SST-hl observations.

The empirical variance-covariance matrices used in this paper were constructed directly by using the residual accelerations. In the future, the variance-covariance matrix can be derived by using the error propagation method from the prior carrier phase and orbital variance-covariance information.

Author Contributions: Resources, J.L.; Funding acquisition, J.L. and X.X.; Conceptualization, X.X.; Data curation, H.W. and K.K.; Investigation, T.W.; Methodology, X.X. and H.W.; Validation, T.W. and H.W.; Writing-original draft, T.W. and X.X.; Writing-review \& editing, J.L., H.W., K.K., and Y.Z.

Funding: This research was funded by the National Natural Science Foundation of China (Grant No. 41574019, 41774020,41804020), the German Academic Exchange Service (DAAD) Thematic Network Project (Grant No. 57421148), The Major Project of High Resolution Earth Observation System, the Civil Space Technology Pre-research Project "Satellite Gradiometry Technology", and the Key Laboratory of Geospace Environment and Geodesy, Ministry of Education, Wuhan University (Grant No. 16-02-08,17-01-10,18-02-04).

Acknowledgments: The numerical calculations in this paper were carried out on the supercomputing system in the Supercomputing Center of Wuhan University. We gratefully acknowledge the European Space Agency for providing the GOCE data and the International GNSS Service for providing the GPS data.

Conflicts of Interest: The authors declare no conflict of interest. 


\section{References}

1. Floberghagen, R.; Fehringer, M.; Lamarre, D.; Muzi, D.; Frommknecht, B.; Steiger, C.; Pineiro, J.; da Costa, A. Mission design, operation and exploitation of the gravity field and steady-state ocean circulation explorer mission. J. Geod. 2011, 85, 749-758. [CrossRef]

2. Reigber, C.; Luhr, H.; Schwintzer, P. CHAMP mission status. Adv. Space Res. 2002, 30, 129-134. [CrossRef]

3. Tapley, B.D.; Bettadpur, S.; Ries, J.C.; Thompson, P.F.; Watkins, M.M. GRACE measurements of mass variability in the Earth system. Science. 2004, 305, 503-505. [CrossRef] [PubMed]

4. Drinkwater, M.R.; Floberghagen, R.; Haagmans, R.; Muzi, D.; Popescu, A. GOCE: ESA's first Earth Explorer Core mission. Space Sci. Rev. 2003, 108, 419-432. [CrossRef]

5. Jekeli, C. The determination of gravitational potential differences from satellite-to-satellite tracking. Celest. Mech. Dyn. Astron. 1999, 75, 85-101. [CrossRef]

6. Reigber, C.; Balmino, G.; Schwintzer, P.; Biancale, R.; Bode, A.; Lemoine, J.M.; Konig, R.; Loyer, S.; Neumayer, H.; Marty, J.C.; et al. A high-quality global gravity field model from CHAMP GPS tracking data and accelerometry (EIGEN-1S). Geophys. Res. Lett. 2002, 14, 1692. [CrossRef]

7. Han, S.C. Efficient determination of global gravity field from satellite-to-satellite tracking mission. Celest. Mech. Dyn. Astron. 2004, 88, 69-102. [CrossRef]

8. Baur, O.; Bock, H.; Höck, E.; Jäggi, A.; Krauss, S.; Mayer-Gürr, T.; Reubelt, T.; Siemes, C.; Zehentner, N. Comparison of GOCE-GPS gravity fields derived by different approaches. J. Geod. 2014, 88, 959-973. [CrossRef]

9. Liu, X. Global Gravity Field Recovery from Satellite-to-Satellite Tracking Data with the Acceleration Approach. Ph.D. Thesis, Delft University of Technology, Delft, The Netherlands, 2008.

10. Pail, R.; Bruinsma, S.; Migliaccio, F.; Förste, C.; Goiginger, H.; Schuh, W.-D.; Höck, E.; Reguzzoni, M.; Brockmann, J.M.; Abrikosov, O.; et al. First GOCE gravity field models derived by three different approaches. J. Geod 2011, 85, 819. [CrossRef]

11. Beutler, G.; Jäggi, A.; Mervart, L.; Meyer, U. The celestial mechanics approach: theoretical foundations. J. Geod. 2010, 84, 605-624. [CrossRef]

12. Weigelt, M.; Sideris, M.G.; Sneeuw, N. On the influence of the ground track on the gravity field recovery from high-low satellite-to-satellite tracking missions: CHAMP monthly gravity field recovery using the energy balance approach revisited. J. Geod. 2009, 83, 1131-1143. [CrossRef]

13. Mayer-Gürr, T.; Ilk, K.H.; Eicker, A.; Feuchtinger, M. ITG-CHAMP01: a CHAMP gravity field model from short kinematic arcs over a one-year observation period. J. Geod. 2005, 78, 462-480. [CrossRef]

14. Reubelt, T.; Austen, G.; Grafarend, E.W. Harmonic analysis of the Earth's gravitational field by means of semi-continuous ephemerides of a low Earth orbiting GPS-tracking satellite. Case study: CHAMP. J. Geod. 2003, 77, 257-278. [CrossRef]

15. Ditmar, P.; van der Sluijs, A.V.E. A technique for modeling the Earth's gravity field on the basis of satellite accelerations. J. Geod. 2004, 78, 12-33. [CrossRef]

16. Ditmar, P.; Kuznetsov, V.; Sluijs, A.; Schrama, E.; Klees, R. 'DEOS_CHAMP-01C_70': A model of the Earth's gravity field computed from accelerations of the CHAMP satellite. J. Geod. 2006, 79, 586-601. [CrossRef]

17. Xu, X.; Zhao, Y.; Reubelt, T.; Tenzer, R. A GOCE only gravity model GOSG01S and the validation of GOCE related satellite gravity models. Geodesy and Geodynamics 2017, 8, 260-272. [CrossRef]

18. Baur, O.; Reubelt, T.; Weigelt, M.; Roth, M.; Sneeuw, N. GOCE orbit analysis: Long-wavelength gravity field determination using the acceleration approach. Adv. Space Res. 2012, 50, 385-396. [CrossRef]

19. Bezděk, A.; Sebera, J.; Klokočník, J.; Kostelecký, J. Gravity field models from kinematic orbits of CHAMP, GRACE and GOCE satellites. Adv. Space Res. 2014, 53, 412-429. [CrossRef]

20. Bruton, A.M.; Glennie, C.L.; Schwarz, K.P. Differentiation for High-Precision GPS Velocity and Acceleration Determination. GPS Solut. 1999, 2, 7-21. [CrossRef]

21. Salazar, D.; Hernandez-Pajares, M.; Juan-Zornoza, J.M.; Sanz-Subirana, J.; Aragon-Angel, A. EVA: GPS-based extended velocity and acceleration determination. J. Geod. 2011, 85, 329-340. [CrossRef]

22. Szarmes, M.; Ryan, S.J.; Lachapelle, G.; Fenton, P. DGPS High Accuracy Aircraft Velocity Determination Using Doppler Measurements. In Proceedings of the International Symposium on Kinematic Systems in Geodesy, Geomatics and Navigation, Banff, AB, Canada, 3-6 June 1997. 
23. Jekeli, C.; Garcia, R. GPS phase accelerations for moving-base vector gravimetry. J. Geod. 1997, 71, 630-639. [CrossRef]

24. Kennedy, S. Acceleration estimate from GPS carrier phases for airborne gravimetry. Master's Thesis, University of Calgary, Calgary, AB, Canada, 2002.

25. Guo, X.; Ditmar, P.; Zhao, Q.; Klees, R.; Farahani, H.H. Earth's gravity field modelling based on satellite accelerations derived from onboard GPS phase measurements. J. Geod. 2017, 91, 1049-1068. [CrossRef]

26. Zehentner, N.; Mayer-Gürr, T.; Heuberger, F. Global Gravity Field Modelling from Orbit Data based on the Acceleration Approach; Scientific Report 5224; Institute of Theretical Geodesy and Satellite Geodesy, Graz University of Technology: Graz, Austria, 2012.

27. Montenbruck, O.; Hackel, S.; Jäggi, A. Precise orbit determination of the Sentinel-3A altimetry satellite using ambiguity-fixed GPS carrier phase observations. J. Geod. 2018, 92, 711-726. [CrossRef]

28. Dow, J.M.; Neilan, R.E.; Rizos, C. The International GNSS Service in a changing landscape of Global Navigation Satellite Systems. J. Geod. 2009, 83, 191-198. [CrossRef]

29. Rummel, R.; Balmoni, G.; Johannessen, J.; Visser, P.; Woodworth, P. Dedicated gravity field missions priciples and aims. J. Geodyn. 2002, 33, 3-20. [CrossRef]

30. Yi, W. An alternative computation of a gravity field model from GOCE. Adv Space Res. 2012, 50, 371-384. [CrossRef]

31. Stanish, E.M. JPL Planetary and Lunar Ephemerides, DE405/LE405. JPL IOM 312. F-98-048. Available online: ftp://ssd.jpl.nasa.gov/pub/eph/planets/ioms/de405.iom.pdf (accessed on 12 June 2019).

32. Petit, G.; Luzum, B. IERS Conventions (2010). Bureau International des Poids et Mesures Sevres (France). 2010. Available online: https://www.iers.org/IERS/EN/Publications/TechnicalNotes/tn36.html (accessed on 1 April 2019).

33. Savcenko, R.; Bosch, W. EOT11a-empirical ocean tide model from multi-mission satellite altimetry; Scientific Report 89; Deutsches Geodätisches Forschungsinstitut, Technische Universität München: München, Germany, 2012.

34. Desai, S.D. Observing the pole tide with satellite altimetry. J. Geophys. Res. Oceans 2002, 107, 3186. [CrossRef]

35. Hofmann-Wellenhof, B.; Moritz, H. Physical Geodesy; Springer Science \& Business Media: Berlin, Germany, 2006.

36. EGG-C. GOCE Level1b Product Data Handbook. GOCE-GSEG-EOPG-TN-06-0137. 2008. Available online: https://earth.esa.int/c/document_library/get_file?folderId=14168\&name=DLFE-772.pdf (accessed on 13 June 2019).

37. EGG-C. GOCE Level 2 Product Data Handbook. GO-MA-HPF-GS-0110. 2010. Available online: https: //earth.esa.int/documents/10174/1650485/GOCE_Product_Data_Handbook_Level-2 (accessed on 13 June 2019).

38. Bouman, J.; Rispens, S.; Gruber, T.; Koop, R.; Schrama, E.; Visser, P.; Tscherning, C.C.; Veicherts, M. Preprocessing of gravity gradients at the GOCE high-level processing facility. J. Geod. 2009, 83, 659-678. [CrossRef]

39. Bock, H.; Jäggi, A.; Beutler, G.; Meyer, U. GOCE: precise orbit determination for the entire mission. J. Geod. 2014, 88, 1047-1060. [CrossRef]

40. Zehentner, N.; Mayer-Gurr, T. Precise orbit determination based on raw GPS measurements. J. Geod. 2016, 90, 275-286. [CrossRef]

41. Farahani, H.; Ditmar, P.; Klees, R.; Liu, X.; Zhao, Q.; Guo, J. The static gravity field model DGM-1S from GRACE and GOCE data: computation, validation and an analysis of GOCE mission's added value. J. Geodyn. 2013, 87, 843-867. [CrossRef]

42. Förste, C.B.; Sean, L.; Abrikosov, O.; Lemoine, J.-M.; Marty, J.C.; Flechtner, F.; Balmino, G.; Barthelmes, F.; Biancale, R. EIGEN-6C4 The Latest Combined Global Gravity Field Model Including GOCE Data up to Degree and Order 2190 of GFZ Potsdam and GRGS Toulouse. Available online: http://icgem.gfz-potsdam. de/getmodel/doc/7fd8fe44aa1518cd79ca84300aef4b41ddb2364aef9e82b7cdaabdb60a9053f1 (accessed on 1 April 2019).

43. Wahr, J.; Molenaar, M.; Bryan, F. Time variability of the Earth's gravity field: Hydrological and oceanic effects and their possible detection using GRACE. J. Geophys. Res. Soild Earth 1998, 103, 30205-30229. [CrossRef]

44. Bock, H.; Jäggi, A.; Svehla, D.; Beutler, G.; Hugentobler, U.; Visser, P. Precise orbit determination for the GOCE satellite using GPS. Adv. Space Res. 2007, 39, 1638-1647. [CrossRef]

45. van den IJssel, J.; Visser, P.; Doornbos, E.; Meyer, U.; Bock, H.; Jäggi, A. GOCE SSTI L2 Tracking Losses and their Impact on POD Performance. In Proceedings of the 4th International GOCE User Workshop, Munich, Germany, 31 March-1 April 2011. 
46. Bock, H.; Jäggi, A.; Meyer, U.; Visser, P.; van den IJssel, J.; van Helleputte, T.; Heinze, M.; Hugentobler, U. GPS-derived orbits for the GOCE satellite. J. Geod. 2011, 85, 807-818. [CrossRef]

47. Jäggi, A.; Bock, H.; Prange, L.; Meyer, U.; Beutler, G. GPS-only gravity field recovery with GOCE, CHAMP, and GRACE. Adv. Space Res. 2011, 47, 1020-1028. [CrossRef]

48. Jäggi, A.; Bock, H.; Meyer, U.; Beulter, G.; van den IJssel, J. GOCE: assessment of GPS-only gravity field determination. J. Geod. 2015, 89, 33-48. [CrossRef]

49. Sneeuw, N.; van Gelderen, M. The polar gap. In Geodetic Boundary Value Problems in View of the One Centimeter Geoid, Lecture Notes in Earth Sciences; Sansò, F., Rummel, R., Eds.; Springer: Berlin/Heidelberg, Germany, 1997; Volume 65, pp. 559-568.

50. Gelderen, M.; Koop, R. The use of degree variances in satellite gradiometry. J. Geod. 1997, 71, $337-343$. [CrossRef]

(C) 2019 by the authors. Licensee MDPI, Basel, Switzerland. This article is an open access article distributed under the terms and conditions of the Creative Commons Attribution (CC BY) license (http://creativecommons.org/licenses/by/4.0/). 